\title{
Eremostachys binalodensis, a potential therapeutic choice for gingival inflammatory wounds
}

\author{
Armin S. Hariri', Sevda Shayesteh², Parina Asgharian³, Mohsen Chamanara ${ }^{4,5}$, Maryam-Sadat Sadrzadeh-Afshar ${ }^{r^{*}}$
}

\author{
'Oral and Maxillofacial Medicine Department, Faculty of Dentistry, Aja University of Medical Sciences, Tehran, Iran \\ 'Department of Pharmacology and Toxicology, Faculty of Pharmacy, Alborz University of Medical Sciences, Karaj, Iran \\ ${ }^{3}$ Department of Pharmacognosy, Faculty of Pharmacy, Tabriz University of Medical Sciences, Tabriz, Iran \\ ${ }^{4}$ Department of Pharmacology, Faculty of Medicine, Aja University of Medical Sciences, Tehran, Iran \\ Toxicology Research Center, Aja University of Medical Sciences, Tehran, Iran \\ ${ }^{6}$ Oral and Maxillofacial Medicine Department, Faculty of Dentistry, Aja University of Medical Sciences, Tehran, Iran \\ *Correspondence to: Maryam-Sadat Sadrzadeh-Afshar, m_sadrzade@alumnus.tums.ac.ir \\ (Submitted:07 April 2021 - Revised version received: 18 April 2021 - Accepted: 27 April 2021 - Published online: 26 June 2021)
}

\begin{abstract}
Objectives In this study we aimed to evaluate the effect of E. binalodensis on gingival inflammatory wounds.

Materials and Methods In-vitro wound was induced by scratching the surface layer of human gingival fibroblasts (hGFs). Cells were retreated with 1,10,100,1000 $\mu \mathrm{g} / \mathrm{ml}$ of E. binalodensis methanol extract prior to $1 \mu \mathrm{g} / \mathrm{ml}$ LPS stimulation. hGFs proliferation was assessed by MTT test. Also levels of critical inflammatory cytokines such as IL-1 $\beta$, IL-6 and TNF- $\alpha$ were determined by enzyme-linked immunosorbent assay (ELISA)

Results Wound induction was associated with secretion of IL-1 $\beta$, IL-6 and TNF- $\alpha$ from hGFs. E. binalodensis enhanced the hGFs proliferation besides reducing the level of IL-1 $\beta$, IL- 6 and TNF- $\alpha$ in LPS-scratch-stimulated hGFs.

Conclusions Regarding anti-inflammatory and proliferative effects of E. binalodensis on hGFs, availability and safety of it, it is suggested for enhancing the wound healing process in gingival inflammatory wounds.

Key words Eremostachys, gingivitis, fibroblast, inflammation, wound
\end{abstract}

\section{Introduction}

Gingiva is the first tissue destructed in periodontal diseases and gingivitis leads to oral cavity complications if remained untreated. The healing process includes 4 main phases hemostasis, inflammation, proliferation and remodeling; and proliferation and migration of fibroblasts, play crucial role in healing process. ${ }^{1}$ Despite a rapid healing process, the presence of bacteria in oral cavity accounts for the complicated wounds accompanied with inflammation. ${ }^{2}$ Chronic increased levels of pro-inflammatory factors such as interleukin (IL-1 $\beta$ ) and Tumor necrosis factor (TNF- $\alpha$ ) activates apoptotic pathways in fibroblasts as well as inducing the production of IL-6 which leads to a positive inflammatory cycle. ${ }^{3,4}$ In addition, inflammation diminishes the migration and proliferation of the cells, resulting in delayed wound healing. ${ }^{5}$ Moreover, enhanced inflammatory response leads to loss of connective tissue attachments and alveolar bone destruction. ${ }^{6}$ On the other hand, the administration of anti-inflammatory drugs such as corticosteroids, decelerate the healing process by reducing the proliferation rate of the fibroblasts as well as decreasing collagen and glycosaminoglycan synthesis. ${ }^{7}$ Therefore, investigating anti-inflammatory agents not impairing the healing process is of great importance for gingiva wounds treatment.

Eremostachys binalodensis is an Iranian endemic specie of Eremostachys genus from Lamiaceae family. It is mostly grown in middle-east and west Asia, having thick roots. Several bioactive compounds have been isolated from the Eremostachysspeciesincluding:terpenoids, mono-and sesquitepenes, linear and branched hydrocarbons and derivatives. ${ }^{9}$ This plant was topically used for wound healing of snake bites and rheumatism joint pains. ${ }^{10}$ The rhizomes, rich in iridoid glycosides, are known for analgesic effects. ${ }^{11}$ In addition, the anti-inflammatory effects of Eremostachys rhizomes have been reported in allergies and auto-immune diseases. ${ }^{12}$ It has been suggested that, attenuating the prostaglandins formation is responsible for Eremostachys anti-inflammatory effects. ${ }^{13}$ Besides mentioned properties, the anti-bacterial effects of Eremostachys on Escherichia coli and Staphylococcus aureus species suggests it for oral wounds and infections which have not been studied yet. ${ }^{14}$

Taking this information into consideration, the purpose of this study was to evaluate the effectiveness of E. Binalodensis on gingival wound healing through altering fibroblast proliferation and secretion of three important inflammatory cytokines.

\section{Materials and Methods}

\section{E. binalodensis extract preparation}

The rhizomes of E. binalodensis were collected on July from Binalud mountains, Mashhad Iran [ $\left(336^{\circ} 17^{\prime} 60.00^{\prime \prime} \mathrm{N}\right)$ latitude ( $\left.58^{\circ} 32^{\prime} 60.00^{\prime \prime} \mathrm{E}\right)$ longitude and altitude $1950 \mathrm{~m}$ above sea level]. A voucher specimen has been deposited in the herbarium of the Faculty of Pharmacy, Tabriz University of Medical Sciences, Iran under the accession code TBZ-FPH 4033.

Air-dried rhizomes of E. binalodensis (100 g each) were extracted with methanol. All obtained extracts were separately concentrated using a rotary evaporator at a maximum temperature of $45^{\circ} \mathrm{C}$

\section{Cell culture}

Human gingival fibroblasts (hGFs) (HGF1-PI 1) were obtained from Pasteur institute, Tehran, Iran. Cells were cultured in 
Dulbecco's modified Eagle medium (Sigma-Aldrich, Germany) including 10\% fetal bovine serum, $2 \mathrm{mM} \mathrm{L}$-glutamine, $100 \mathrm{mM}$ L-ascorbate-2-phosphate, $50 \mathrm{U} / \mathrm{mL}$ streptomycin, $50 \mathrm{U} / \mathrm{mL}$ penicillin and $1 \mathrm{mM}$ sodium pyruvate. ${ }^{15}$ Cells were seeded $\left(1 \times 10^{5}\right.$ cells/well $)$ in 24 -well plates and incubated for 24 hours in $37^{\circ} \mathrm{C}, 5 \% \mathrm{CO}_{2}$ and $95 \%$ humidity.

\section{In-vitro wound and LPS induction}

In-vitro wound was induced by scrapping the $2-3 \mathrm{~mm}$ of surface layer of hGFs creating a scratch to the cells followed by mentioned incubation method. ${ }^{16}$ In order to induce inflammation, $1 \mu \mathrm{g} / \mathrm{ml}$ bacterial endotoxin (Lipopolysaccharides (LPS)) was added 1 hour after E. binalodensis extract application on cells.

\section{Experimental groups}

First, the effective concentration of E. binalodensis on hGFs' proliferation was determined by 3-(4,5-dimethylthiazol-2-yl)-2,5-diphenyl-2H-tetrazolium bromide (MTT) test. $1,10,100$ and $1000 \mu \mathrm{g} / \mathrm{ml}$ of the methanolic E. binalodensis extracts in $1 \%$ Dimethyl sulfoxide (DMSO) were selected for MTT test.

Regarding the results of MTT test, the work was performed in five groups: 1. Control, 2. Scratch, 3. Scratch + Extract, 4. Scratch + LPS, 5. Scratch + LPS + Extract. Groups 1, 2, 4 were pretreated with the same amount of DMSO. Extract was performed 1 hour prior to LPS and scratch and cells were incubated for 48 hours.

\section{MTT assay}

The effect of E. binalodensis on hGFs proliferation was assessed by MTT test. MTT assay is based on the reduction of MTT to formazan crystals by mitochondria of viable cells. ${ }^{17}$ First, cells which were 48 hours incubated with 1, 10, 100 and $1000 \mu \mathrm{g} / \mathrm{ml}$ of the methanolic extracts of E. binalodensis, were seeded at a density of $1 \times 10^{4}$ cells/well in a 96-well plate. Second, the medium was removed and $10 \mu \mathrm{L}$ MTT was added to the wells and incubated for 4 hours. After observing formazan crystals, $200 \mu \mathrm{L}$ DMSO was added to dissolve the crystals. Finally, the absorbance of the plate was read at $450 \mathrm{~nm}$ by spectrophotometer (Specord 250, Analytik Jena), cell viability was expressed relative to the control group which was regarded as $100 \%$. The test was repeated three times.

\section{ELISA assay of inflammatory markers}

In order to evaluate the main inflammatory markers involved in periodontal diseases, the protein levels of IL- $1 \beta$, IL- 6 and TNF- $\alpha$ in culture supernatants were measured by enzymelinked immunosorbent assay (ELISA). Human IL- $1 \beta$ ELISA Kit (ab100562), Human TNF alpha ELISA Kit (ab181421), Human IL-6 ELISA Kit (ab46027) were purchased. For this purpose, $50 \mu \mathrm{L}$ of cells were added to a 96 -well plate. $50 \mu \mathrm{L}$ of the antibody cocktail, regarding the type of measured marker, was added to each well and incubated for 2 hours on a plate shaker with $400 \mathrm{rpm}$. After washing the plate regarding the kit instruction, $100 \mu \mathrm{L}$ 3,3',5,5'-Tetramethylbenzidine (TMB) development solution was added and incubated. Finally, after washing and adding the stop solution, the plate absorbance was read at $450 \mathrm{~nm}$ by spectrophotometer. The levels of IL-1 $\beta$, L- 6 and TNF- $\alpha$ in cell culture supernatants, expressed as $\mathrm{pg} / \mathrm{mL}$, were quantified based on each corresponding standard curve. Each experiment was repeated three times.

\section{Statistical analysis}

The data was analyzed by GraphPad Prism 6 through one-way analysis of variance with post-hoc Tukey tests. In this study, $P<0.05$ was considered a significant difference.

\section{Results}

\section{Effect of E. binalodensis on hGFs proliferation}

Effects of E. binalodensis on hGFs proliferation was evaluated by MTT assay. As shown in Figure 1, the cell viability did not change by 1 and $10 \mu \mathrm{g} / \mathrm{ml}$ of extract; However, 100 and 1000 $\mu \mathrm{g} / \mathrm{ml}$ E. binalodensis extract enhanced the hGFs proliferation significantly $(P<0.001, P<0.0001)$. The results illustrated the proliferative effect of $E$. binalodensis on hGFs. Considering MTT test results, $100 \mu \mathrm{g} / \mathrm{ml}$ of E.binalodensis, the lowest proliferative concentration in this research, was selected for further ELISA tests.

\section{Effect of E. binalodensis on production of IL-1 $\beta$ in LPS-stimulated hGFs}

As presented in figure 2, scratch induction raised the IL-1 $\beta$ significantly compared to control group $(P<0.01)$. Also, LPS application (scratch + LPS group) induced $1 \mathrm{~L}-1 \beta$ significantly in comparison with scratch group $(P<0.0001)$. However, $E$. binalodensis administration significantly reduced the IL- $1 \beta$ level in comparison with scratch + LPS group $(P<0.0001)$.

\section{Effect of E. binalodensis on production of IL-6 in LPS-stimulated hGFs}

Regarding figure 3, IL-6 elevated in scratch group compared to control group $(P<0.05)$. In addition, $E$. binalodensis extract application reduced the IL-6 level in comparison with scratch

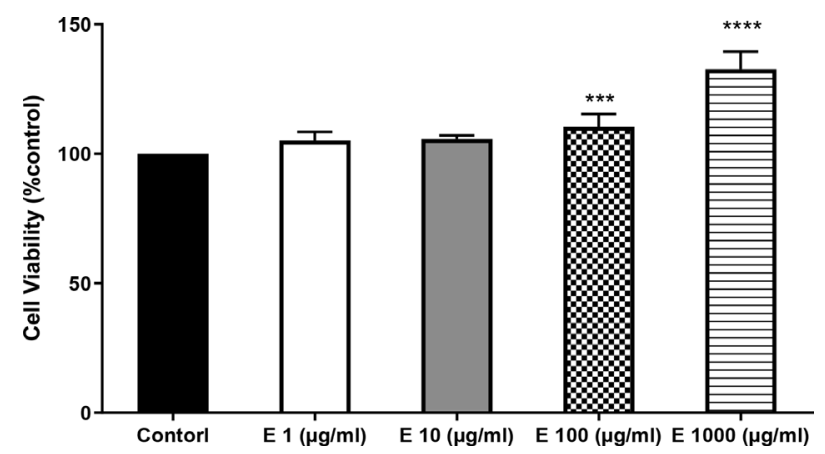

Fig. 1 The effect of $E$. binalodensis on hGFs proliferation. E: Eremostachys Binalodensis. ( ${ }^{* * * *} P<0.001,{ }^{* * * * *} P<0.0001$ compared to control group). Data are presented as Mean \pm SD.

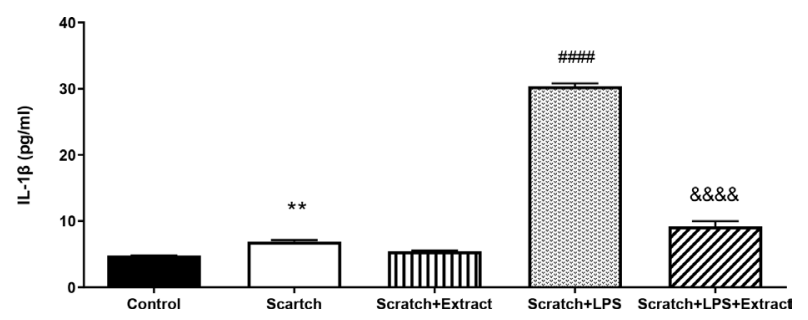

Fig. 2 Effect of $E$. binalodensis on production of IL-1 $\beta$ in LPSstimulated hGFs. Data are presented as Mean \pm SEM. ${ }^{{ }^{* *} P} P<0.01$ compared to control group, \#\#\#P<0.0001 compared to scratch group, ${ }^{\text {\&\&\& } P}<0.0001$ compared to scratch + LPS group). 


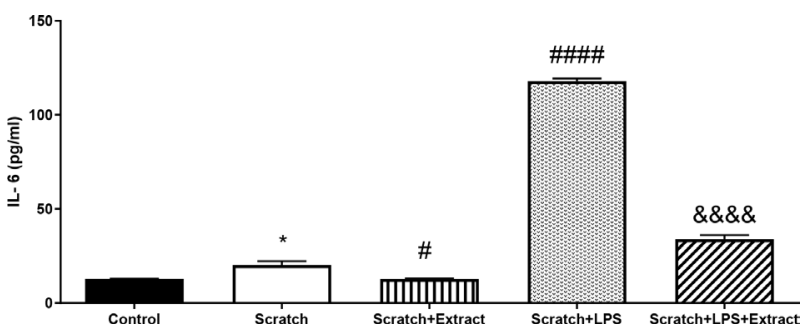

Fig. 3 Effect of E. binalodensis on production of IL- 6 in LPSstimulated hGFs. Data are presented as Mean \pm SEM. ( $P<0.05$ compared to control group, ${ }^{\#} P<0.05$ and ${ }^{\# \# \# \#<0.0001 \text { com- }}$ pared to scratch group, ${ }^{\text {\&\&\& }} P<0.0001$ compared to scratch + LPS group).

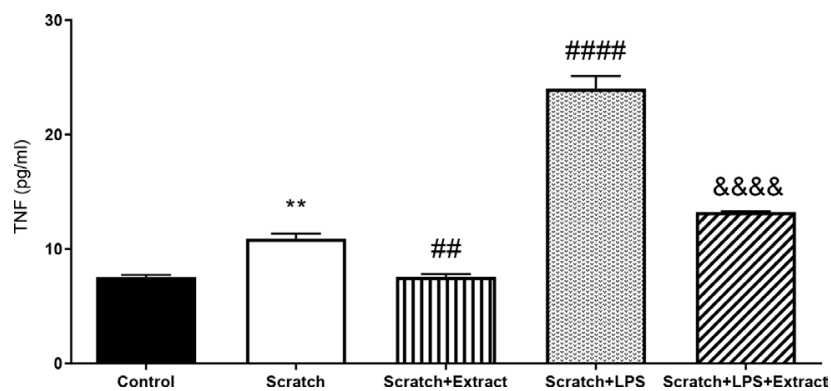

Fig. 4 Effect of $E$. binalodensis on production of TNF- $\alpha$ in LPSstimulated hGFs. Data are presented as Mean \pm SEM. $\left({ }^{* *} P<0.01\right.$ compared to control group, ${ }^{\# \#} P<0.05$ and ${ }^{\# \# \# P<0.0001 \text { compared }}$ to scratch group, ${ }^{\text {\&\&\& } P} P<0.0001$ compared to scratch + LPS group).

group $(P<0.05)$. LPS induction (scratch + LPS group), raised the IL-6 level significantly compared to scratch group $(P<0.0001)$. In contrast, E. binalodensis extract administration significantly decreased the IL-6 level compared to scratch + LPS group $(P<0.0001)$.

\section{Effect of E. binalodensis on production of TNF- $\alpha$ in LPS-stimulated hGFs}

As shown in figure 4, TNF- $\alpha$ significantly increased in scratch-applied group in comparison with control group $(P<0.05, P<0.0001)$. In group receiving $E$. binalodensis extract, TNF- $\alpha$ level declined significantly in comparison with scratch group $(P<0.05)$. Similarly, LPS administration (scratch + LPS group) induced TNF- $\alpha$ compared to scratch group $(P<0.0001)$. Contrarily, E. binalodensis extract administration reduced the TNF- $\alpha$ level when compared to scratch + LPS group $(P<0.0001)$.

\section{Discussion}

In the present study, we evaluated the possible effect of $E$. binalodensis on gingival inflammatory wounds. Gingival wounds, leading in gingivitis, are the first stage of periodontal diseases. In comparison with dermal or mucosal wounds, gingival wounds are thought to be more complicated due to presence of microbial plaques, low accessibility of mouthwashes and antimicrobial agents to the bacteria and $\mathrm{pH}$ variations. ${ }^{18}$ The untreated gingivitis can lead to periodontal disease accompanied with sever medical conditions such as cardiovascular disease, diabetes, and adverse pregnancy outcomes. ${ }^{19}$

Inflammation is regarded as the first stage of healing process of gingival wounds followed by fibroblast-mediated tissue formation and remodeling. ${ }^{20}$ It starts with infiltration of leukocytes to the wound site, resulting in pathogen combating, tissue degradation and regeneration. ${ }^{21}$ However, excessive inflammatory response diminishes mitogenic cell activity and tissue remodeling. ${ }^{22}$

In this study, it was observed that IL- $1 \beta$ was elevated in scratched fibroblasts, confirming fibroblasts as one of the major sources of IL-1 $\beta$. It has been reported that, besides fibroblasts the accumulated neutrophils post-injury, produce pro-inflammatory cytokines such as IL- $1 \beta$ and TNF- $\alpha .{ }^{23}$ LPS or pathogen-activated Toll-like receptors induce Nuclear factor kappa B (NF-kB) expression which results in pro IL-1 $\beta$ production. ${ }^{24}$ IL-1 $\beta$ increases neutrophil infiltration and triggers inflammatory cascades in wound area. Also, elevated levels of IL-1 $\beta$ induces prostaglandin E2 formation, together inducing collagenase which leads to periodontal attachment loss. ${ }^{25}$ Moreover, IL-1 $\beta$ stimulated matrix metalloproteinases, contribute in extracellular matrix degradation and tissue destruction. ${ }^{26}$ In contrast, our results showed that $E$. binalodensis markedly decreases the scratch + LPSinduced IL-1 $\beta$ level. It has been reported that there is a strong relationship between increasing gingival cervical fluid levels of IL- $1 \beta$ and severity of gingivitis and blocking IL- $1 \beta$ activity or reducing it by anti-inflammatory agents, have improving effects on gingivitis. ${ }^{27,28}$

Similarly, in this research TNF- $\alpha$ was elevated postscratch in fibroblasts. TNF- $\alpha$ is involved in late steps of wound healing, shifting the cells to tissue remodeling phase; however, increased levels of it results in tissue damaging by impairing fibroblast activity and stimulating osteoclastogenesis. ${ }^{29}$ Also TNF- $\alpha$ induces fibroblast apoptosis through Foxo signaling pathway. ${ }^{30}$ Although increase of TNF- $\alpha$ level was observed following scratch + LPS application, pretreatment with E.binalodensis attenuated the TNF- $\alpha$ rise in fibroblasts. Regarding the synergistic effects of IL- $1 \beta$ and TNF- $\alpha$, it has been reported that administration of antagonists of both cytokines has more beneficial effects on gingivitis. ${ }^{27}$

Moreover, the level of IL-6, one of the predictors of periodontal disease initiation, was evaluated in this study. The results showed that, both scratch and LPS induction increases the IL-6 level. It is suggested that, enhanced levels of IL-1 $\beta$ and TNF- $\alpha$ are involved in stimulating fibroblast-secretion of IL-6 through mitogen-activated protein kinase (MAPK) pathway, resulting in positive inflammatory feedback. ${ }^{31}$ IL-6 is highly associated with the pocket depth and severity of gingivitis. ${ }^{32}$ Also the differentiation of CD4 to T cells is impaired by high levels of IL-6, resulting in reduced bacterial inhibition in oral cavity. ${ }^{33}$ In addition, IL-6, known as stimulator of osteoclasts, is responsible for bone resorption followed by gingivitis. ${ }^{34}$ Our results showed that E.binalodensis reduced the IL-6 level post scratch as well as post LPS application. Similarly, it has been shown that, agents reducing IL-6, decrease bone loss in inflamed gingival mucosa. Also Tocilizumab (IL-6 receptor inhibitor) administration have been reported to improve gingivitis and reduce bleeding sites. ${ }^{35}$ Therefore, E. binalodensis inhibits inflammation-induced complications by reducing the secretion of three critical pro-inflammatory cytokines. The potential anti-bacterial effects of Eremostachys genius, have been reported in previous studies. ${ }^{14}$ Besides inhibiting inflammation, anti-bacterial effects of $E$. binalodensis may enhance the gingival wound healing process. 
The second stage in reformation of periodontal tissue centrally involves fibroblasts, which generate and organize the collagen fibers that attach the alveolar bone and gingiva to the cementum covering the tooth root. ${ }^{36}$ In this study, it was observed that E.binalodensis extract, not only reduces the inflammatory cytokines, but also enhances the fibroblast proliferation. This is the remarkable feature of proposing E. binalodensis for gingival wounds. The increased rate of gingival fibroblast proliferation, results in enhanced wound healing process. Our results are similar to Liao et al. study indicating that, traditional medicine inhibiting IL-6 and inducing fibroblast proliferation are suggested for gingival wound healing. ${ }^{37}$ The treatment choices for gingivitis include anti-inflammatory drugs which usually impair fibroblast activation. ${ }^{7}$ Regarding the crucial role of fibroblasts in gingival wound healing, it is of a great importance to administer agents that prevent inflammation without attenuating fibroblast proliferation and activity. Regarding the previous studies, it is suggested that the anti-inflammatory effects of E. binalodensis is related to the presence of iridoid glycosides in this plant. ${ }^{13}$
Taken together, it can be concluded that, the methanol extract of E. binalodensis has improving effects on inflammatory gingival wounds. Also availability of this plant and previouslyconfirmed safety of it, reduces the cost of treatment besides enhancing the healing process. Further in-vivo investigations can be applied for evaluating the effects of E. binalodensis in details.

\section{Funding Sources}

This study was supported by Aja University of Medical Sciences (Grant:97001404).

\section{Acknowledgment}

The authors would like to thank Sara laboratory (Tabriz, Iran) and Pharmacognosy department of Tabriz University of Medical Sciences for their contribution in this study.

\section{Conflicts of Interest}

The authors have no conflicts of interest to disclose.

\section{References}

1. Smith PC, Cáceres M, Martínez C, Oyarzún A, Martínez J. Gingival Wound Healing: An Essential Response Disturbed by Aging? Journal of Dental Research. 2015;94:395-402.

2. Bhattacharya R, Xu F, Dong G, Li S, Tian C, Ponugoti B, et al. Effect of bacteria on the wound healing behavior of oral epithelial cells. PloS one. 2014;9:e89475

3. Palmqvist $P$, Lundberg $P$, Lundgren I, Hänström L, Lerner U. IL-1 $\beta$ and TNF- $\alpha$ regulate IL-6-type cytokines in gingival fibroblasts. Journal of dental research. 2008;87:558-63.

4. Shirasugi M, Nishioka K, Yamamoto T, Nakaya T, Kanamura N. Normal human gingival fibroblasts undergo cytostasis and apoptosis after longterm exposure to butyric acid. Biochemical and biophysical research communications. 2017:482:1122-8.

5. Basso FG, Soares D, Pansani T, Turrioni A, Scheffel D, de Souza Costa C, et al. Effect of LPS treatment on the viability and chemokine synthesis by epithelial cells and gingival fibroblasts. Archives of oral biology. 2015:60:1117-21.

6. Taylor JJ. Protein biomarkers of periodontitis in saliva. International Scholarly Research Notices. 2014;2014.

7. Roques $C$, Téot L. The use of corticosteroids to treat keloids: a review. The international journal of lower extremity wounds. 2008;7:137-45.

8. Mozaffarian V. A dictionary of Iranian plant names. Tehran: Farhang Moaser. 1996;396.

9. Asgharian P, Delazar A, Asnaashari S. Chemical Constituents of Eremostachys macrophylla Montbr. \& Auch. Aerial Parts. Pharmaceutical Sciences. 2020;26:203-8.

10. Mosaddegh M, Naghibi F, Moazzeni H, Pirani A, Esmaeili S. Ethnobotanical survey of herbal remedies traditionally used in Kohghiluyeh va Boyer Ahmad province of Iran. Journal of ethnopharmacology. 2012;141:80-95.

11. Khan S, Nisar M, Simjee SU, Rehman W, Khan R, Jan I, et al. Evaluation of micronutrients level and antinociceptive property of Eremostachys laciniata (L) Bunge. African Journal of Biotechnology. 2010;9.

12. Delazar A, Sarker SD, Nahar L, Jalali SB, Modaresi M, Hamedeyazdan S, et al. Rhizomes of Eremostachys laciniata: isolation and structure elucidation of chemical constituents and a clinical trial on inflammatory diseases. Advanced pharmaceutical bulletin. 2013:3:385

13. Khan S, Nisar M, Rehman W, Khan R, Nasir F. Anti-inflammatory study on crude methanol extract and different fractions of Eremostachys laciniata. Pharmaceutical biology. 2010;48:1115-8.

14. Modaressi M, Delazar A, Nazemiyeh H, Fathi-Azad F, Smith E, Rahman MM, et al. Antibacterial iridoid glucosides from Eremostachys laciniata. Phytotherapy Research: An International Journal Devoted to Pharmacological and Toxicological Evaluation of Natural Product Derivatives. 2009;23:99-103.

15. Xiong G, Ji W, Wang F, Zhang F, Xue P, Cheng M, et al. Quercetin inhibits inflammatory response induced by LPS from Porphyromonas gingivalis

in human gingival fibroblasts via suppressing NF-kB signaling pathway. BioMed research international. 2019;2019.

16. Weinreb M, Nemcovsky CE. In vitro models for evaluation of periodontal wound healing/regeneration. Periodontology 2000. 2015;68:41-54.

17. Xiong $G$, Ji W, Wang F, Zhang F, Xue $P$, Cheng $M$, et al. Quercetin inhibits inflammatory response induced by LPS from porphyromonas gingivalis in human gingival fibroblasts via suppressing NF-kB signaling pathway. BioMed research international. 2019.

18. Politis C, Schoenaers J, Jacobs R, Agbaje JO. Wound healing problems in the mouth. Frontiers in physiology. 2016;7:507.

19. Nazir MA. Prevalence of periodontal disease, its association with systemic diseases and prevention. International journal of health sciences. 2017;11:72

20. Ahangar P, Mills SJ, Smith LE, Gronthos S, Cowin AJ. Human gingival fibroblast secretome accelerates wound healing through anti-inflammatory and proangiogenic mechanisms. NPJ Regenerative medicine. 2020;5:1-10.

21. Polimeni G, Xiropaidis AV, Wikesjö UM. Biology and principles of periodontal wound healing/regeneration. Periodontology 2000. 2006;4:30-47.

22. Chiquet $M$, Katsaros C, Kletsas D. Multiple functions of gingival and mucoperiosteal fibroblasts in oral wound healing and repair. Periodontology 2000. 2015;68:21-40.

23. Schett G, Dayer J-M, Manger B. Interleukin-1 function and role in rheumatic disease. Nature Reviews Rheumatology. 2016;12:14

24. Cheng R, Wu Z, Li M, Shao M, Hu T. Interleukin-1 $\beta$ is a potential therapeutic target for periodontitis: a narrative review. International journal of oral science. 2020:12:1-9.

25. Reinhardt RA, Masada MP, KaldahI WB, DuBois LM, Kornman KS, Choi Jl, et al. Gingival fluid IL-1 and IL-6 levels in refractory periodontitis. Journal of clinical periodontology. 1993;20:225-31.

26. Kobayashi M, Squires GR, Mousa A, Tanzer M, Zukor DJ, Antoniou J, et al. Role of interleukin-1 and tumor necrosis factor $\alpha$ in matrix degradation of human osteoarthritic cartilage. Arthritis \& Rheumatism: Official Journal of the American College of Rheumatology. 2005;52:128-35.

27. Zhang X, Kohli M, Zhou Q, Graves DT, Amar S. Short-and long-term effects of IL-1 and TNF antagonists on periodontal wound healing. The journal of immunology. 2004;173:3514-23.

28. Oh H, Hirano J, Takai H, Ogata Y. Effects of initial periodontal therapy on interleukin-1 $\beta$ level in gingival crevicular fluid and clinical periodontal parameters. Journal of oral science. 2015;57:67-71.

29. Nathan C. Points of control in inflammation. Nature. 2002:420:846-52.

30. Declercq W, Denecker G, Fiers W, Vandenabeele P. Cooperation of both TNF receptors in inducing apoptosis: involvement of the TNF receptorassociated factor binding domain of the TNF receptor 75 . The Journal of Immunology. 1998;161:390-9.

31. Xiao W, Hodge DR, Wang L, Yang X, Zhang X, Farrar WL. NF-kappaB activates IL-6 expression through cooperation with c-Jun and IL6-AP1 
site, but is independent of its IL6-NFkappaB regulatory site in autocrine human multiple myeloma cells. Cancer biology \& therapy. 2004:3:1007-17

32. Johannsen A, Rydmark I, Söder B, Åsberg M. Gingival inflammation, increased periodontal pocket depth and elevated interleukin-6 in gingiva crevicular fluid of depressed women on long-term sick leave. Journal of periodontal research. 2007;42:546-52.

33. Lin S-J, Chen Y-L, Kuo MY-B, Li C-L, Lu H-K. Measurement of gp130 cytokines-Oncostatin $\mathrm{M}$ and IL-6 in gingival crevicular fluid of patients with chronic periodontitis. Cytokine. 2005;30:160-7.

34. Choi DH, Moon IS, Choi BK, Paik JW, Kim YS, Choi SH, et al. Effects of sub-antimicrobial dose doxycycline therapy on crevicular fluid MMP-8, and gingival tissue MMP-9, TIMP-1 and IL-6 levels in chronic periodontitis. Journal of periodontal research. 2004;39:20-6.

35. Ancuța C, Chirieac R, Ancuța E, Țănculescu O, Solomon SM, Fătu AM, et al. Exploring the Role of Interleukin-6 Receptor Inhibitor Tocilizumab in Patients with Active Rheumatoid Arthritis and Periodontal Disease. Journal of Clinical Medicine. 2021;10:878.

36. Smith PC, Martínez C, Martínez J, McCulloch CA. Role of fibroblast populations in periodontal wound healing and tissue remodeling. Frontiers in physiology. 2019;10:270.

37. Liao J, Azelmat J, Zhao L, Yoshioka M, Hinode D, Grenier D. The Kampo medicine Rokumigan possesses antibiofilm, anti-inflammatory, and wound healing properties. BioMed research international. 2014;2014.

This work is licensed under a Creative Commons Attribution-NonCommercial 3.0 Unported License which allows users to read, copy, distribute and make derivative works for non-commercial purposes from the material, as long as the author of the original work is cited properly. 